\title{
Letter to the Editor on the surgical castration of piglets
}

\section{Dear Editor,}

We would like to raise a number of concerns with regard to the recent paper by Gerritzen et al., entitled 'Castration of piglets under $\mathrm{CO}_{2}$-gas anaesthesia' (Animal, 2008, 2(11), 1666-1673).

While we endorse the motivation of the authors in addressing the welfare problems created by castration of piglets without anaesthesia, especially in light of recent Dutch legislation, we believe that taking the approach outlined in this paper will not ameliorate the problems but will, in fact, compound them. Their aim was to 'examine whether or not $\mathrm{CO}_{2}$ gas is capable of inducing an acceptable anaesthetic state during which castration can be performed' (abstract - emphasis added); this was determined by the piglet being rendered 'insensible and unconscious' through inhalation of $70 \% \mathrm{CO}_{2}+30 \% \mathrm{O}_{2}$ as a putative anaesthetic agent.

The requirements of balanced anaesthesia are widely accepted by medical and veterinary authorities. Thurman and Short (2007) states that a general anaesthetic must relax muscles, induce hypnosis and provide analgesia. While $\mathrm{CO}_{2}$ provides muscle relaxation and hypnosis at high doses, its effect on noiception may be immediate amplification, rather than reduction or cessation, even with concurrent hyperoxygenation (Dripps and Comroe, 1947; McArdle, 1959).

Inhalation of $\mathrm{CO}_{2}$ in mammals elicits high levels of mucosal discomfort due to acidification (Anton et al., 1992) and has been used in models of acute stress (Barbaccia et al., 1996) and pain (Anton et al., 1992). Leach et al. (2002) conclude that $\mathrm{CO}_{2}$, either alone or in combination with argon, cannot be used humanely as a euthanasia agent, at any concentration. The systemic damage caused by elevated $\mathrm{CO}_{2}$ is reported to include pulmonary oedema, emphysema, oedema of perivascular connective tissue in the lungs and myocardial tissue degeneration; these effects have been observed in a variety of species at concentrations as low as $50 \%$ (Conlee et al., 2005). This physical damage, which contravenes the ethical principle of non-maleficence, may cause lasting negative health effects and leave the animal prone to conditions such as respiratory disease. These chronic effects of $\mathrm{CO}_{2}$ inhalation suggest that the authors' proposed method of inducing anaesthesia in piglets requires further study to determine lasting negative effects.

We also have significant concerns about other aspects of this research, which suggest that using inhalation of $70 \%$ $\mathrm{CO}_{2}+30 \% \mathrm{O}_{2}$ to anaesthetise piglets is unacceptable. First, gasping is a response to an aversive stimulus, which indicates distress, suffocation or respiratory arrest (BecerrilHerrera et al., 2009). This concentration of $\mathrm{CO}_{2}$ would induce a sensation of unachievable respiratory satiation akin to asphyxia. Second, all animals convulsed following loss of posture but, critically, convulsions occurred prior to unconsciousness; this is not a feature of an acceptable anaesthetic agent and is a physical sign that would exclude the use of this mixture as an euthanasia inhalant (American Veterinary Medical Association, 2004). These convulsions could be explained as voluntary escape attempts (Raj and Gregory, 1995 and 1996), perhaps associated with decreasing levels of consciousness or they may be due to fear, pain and suffering (European Food Safety Authority, 2004). Third, the lactic acidosis, hyperglycaemia and elevated $\mathrm{PCO}_{2}$ observed in all piglets have been used as measures of physiological stress (Pollard et al., 2002). Fourth, a mortality rate of $50 \%$ (data ambiguous in the paper) and a high morbidity were reported; up to $10 \%$ of the piglets undergoing the procedure may still have remained conscious according to the electroencephalography data. Finally, an electrocardiograph measures electrical activity of the heart and does not always correlate with heart function as stated.

We find it hard to accept that rendering an animal unconscious in a stressful and highly noxious manner, that may be effective in only $90 \%$ of animals, has a dangerously high morbidity and mortality rate, provides no post-operative analgesia and with known immediate aversive effects and unknown long-term effects, is an improvement upon conscious castration. The authors' claim that this method offers a humane alternative to testicular local anaesthesia has not been justified, in our opinion. We also suggest that the authors should use the standardised veterinary criteria before attempting to demonstrate the efficacy of a potential anaesthetic.

Yours sincerely,

Angela J. Wright BSC, MSc (Oxon)

Martin Whiting BSC BVetMed MRCVS

Alan Taylor BSc BVSc CertVA MRCVS

\section{References}

Anton F, Euchner I and Handwerker HO 1992. Psychophysical examination of pain induced by defined $\mathrm{CO}_{2}$ pulses applied to the nasal mucosa. Pain 49, 53-60.

American Veterinary Medical Association 2004. AVMA Guidelines on Euthanasia. Retrieved December 12, 2008, from http://www.avma.org/issues/ animal_welfare/euthanasia.pdf 
Barbaccia ML, Roscetti G, Trabucchi M, Mostallino MC, Concas A, Purdy RH and Biggio G 1996. Time-dependent changes in rat brain neuroactive steroid concentrations and GABAA receptor function after acute stress. Neuroendocrinology 63, 166-172.

Becerril-Herrera M, Alonso-Spilsbury M, Lemus-Flores C, Guerrero-Legarreta I, Olmos-Hernández A, Ramírez-Necoechea R and Mota-Rojas D 2009. $\mathrm{CO}_{2}$ stunning may compromise swine welfare compared with electrical stunning. Meat Science 81, 233-237.

Conlee KM, Stephens ML, Rowan AN and King LA 2005. Carbon dioxide for euthanasia: concerns regarding pain and distress, with special reference to mice and rats. Laboratory Animal 39, 137-161.

Dripps RD and Comroe JH Jr 1947. The respiratory and circulatory response of normal man to inhalation of 7.6 and 10.4 per cent $\mathrm{CO}_{2}$ with a comparison of the maximal ventilation produced by severe muscular exercise, inhalation of $\mathrm{CO}_{2}$ and maximal voluntary hyperventilation. American Journal Physiology 149, 43-51. European Food Safety Authority 2004. Welfare aspects of the main systems of stunning and killing the main commercial species of animals. The EFSA Journal 45, 1-29.

Gerritzen MA, Kluivers-Poodt M, Reimert HGM, Hindle V and Lambooij E 2008. Castration of piglets under $\mathrm{CO}_{2}$-gas anaesthesia. Animal 2, 1666-1673.
Leach MC, Bowell VA, Allan TF and Morton DB 2002. Degrees of aversion shown by rats and mice to different concentrations of inhalational anaesthetics. The Veterinary Record 150, 808-815.

Thurman CJ and Short CE 2007. History and overview of veterinary anesthesia. In Lumb and Jones' Veterinary anesthesia and analgesia, 4th edition. Blackwell Scientific, Ames, IA.

Mcardle L 1959. Electrocardiographic studies during the inhalation of 30 per cent carbon dioxide in man. British Journal of Anaesthesia 31, 142-151

Pollard JC, Littlejohn RP, Asher GW, Pearse AJT, Stevenson-Barry JM, McGregor SK, Manley TR, Duncan SJ, Sutton CM, Pollock KL and Prescott J 2002. A comparison of biochemical and meat quality variables in red deer (Cervus elaphus) following either slaughter at pasture or killing at a deer slaughter plant. Meat Science 60, 85-94.

Raj ABM and Gregory NG 1995. Welfare implications of the gas stunning of pigs. 1. Determination of aversion to the initial inhalation of carbon dioxide or argon. Animal Welfare 4, 273-280.

Raj ABM and Gregory NG 1996. Welfare implications of the gas stunning of pigs. 2. Stress of induction of anaesthesia. Animal Welfare 5, 71-78 